\title{
SOLICITED VERSUS UNSOLICITED RATINGS: THE ROLE OF SELECTION
}

\author{
ANNA GIBERT \\ Statale University of Milan \\ Bocconi University and DIW Berlin \\ Via Festa del Perdono 7, 20122 Milan, Italy \\ anna.gibert@unibocconi.it
}

Received 8 November 2019

Accepted 11 December 2019

Published 15 January 2020

\begin{abstract}
This paper analyzes the extent to which selection explains the observed discrepancy between solicited and unsolicited ratings. I propose a model of selection with truth telling rating agencies and borrowers with the ability to veto the revelation of the rating. The observed difference between the two categories of ratings in different sectors is in line with the prediction of the model. In the sovereign market there is a positive selection of borrowers into unsolicited ratings whereas other sectors have, on the contrary, lower unsolicited rating grades than those solicited.
\end{abstract}

Keywords: Unsolicited ratings; sovereign debt; rating agencies; ancillary services.

JEL Classification: G24, H63, G20

\section{Introduction}

Credit rating agencies (CRAs) are financial intermediaries that give opinions on the creditworthiness of borrowers. Most rating agencies operate under the issuer-pays business model (White 2010), whereby they produce a rating upon solicitation from a potential borrower. CRAs may also give unsolicited ratings without the consent or participation of the borrower.

Much of the academic discussion focuses on whether unsolicited ratings are downward biased. Downward biased ratings mean that borrowers with an unsolicited rating receive a lower rating grade than they would receive if they solicited a rating. This outcome is often interpreted as evidence of the rating agencies'

This is an Open Access article published by World Scientific Publishing Company. It is distributed under the terms of the Creative Commons Attribution 4.0 (CC BY) License which permits use, distribution and reproduction in any medium, provided the original work is properly cited. 
strategic behavior, with the aim of pressuring borrowers into paying for the full service.

Empirical evidence has indeed shown that, in the case of the Asian corporate sector and the non-US financial sector, the group of firms with unsolicited ratings has a lower mean grade than the group of firms with solicited ratings. For instance, Poon \& Firth (2005) study a sample of international banks rated by Fitch in 2002 and find that lower unsolicited ratings cannot be accounted for with fundamentals. They confirm this result using a sample of nonfinancial firms rated by Standard and Poor's (S\&P) between 1998 and 2003 (Poon \& Chan 2010). Similarly, Bannier et al. (2010) find lower ex-post default rates for the group of S\&P unsolicited non-US banks between 1996 and 2006 and argue that this result suggests unsolicited bank ratings are driven by strategic factors. In a sample of Asian banks rated by Fitch in 2004, Van Roy (2013) finds further evidence that unsolicited bank ratings are lower than solicited ones and concludes that there is no support for selection bias. This evidence is compatible with two explanations: strategic behavior on the part of the CRA and selection of borrowers into different solicitation categories. It is still unclear what explanation dominates.

In this paper, I present new evidence challenging the notion that unsolicited ratings are lower than solicited ratings for all sectors. I show that the sovereign market is an example of positive selection of more creditworthy borrowers into the group of solicited ratings. That makes the average rating grade higher for sovereigns with unsolicited ratings vis-à-vis solicited ratings. Controlling for the fundamentals of the country does not eliminate this gap. In the financial sector, on the contrary, unsolicited ratings are lower grades than solicited ratings, looking at borrowers with similar financial characteristics. In a regression of stock prices on the solicitation status, controlling for the rating grades, I find that unsolicited ratings are associated with a worse stock performance. This empirical evidence is in favor of the selection explanation.

I present a simple model of credit ratings, where the rating agency provides accurate information about the signal they receive about the creditworthiness of a borrower. When the probability of getting an unsolicited rating is high enough, less creditworthy borrowers are more afraid of receiving an unsolicited rating. ${ }^{\text {" This }}$ seems to be a plausible feature, as unsolicited ratings are not equally undesirable to all types of borrowers, particularly for those who suspect that they are likely to receive a bad evaluation. When these borrowers have the option to take action to decrease their chances of being exposed (such as asking for a confidential evaluation and revealing the results only if they are good), they will choose to do so if the return from pooling with the group of nonrated borrowers of unobserved quality is

\footnotetext{
a Fulghieri et al. (2014), in contrast, develop a model of strategic unsolicited ratings, where good borrowers are more adversely affected by the possibility of the rating agencies issuing an unfair low rating as a punishment.
} 
high enough. The withdrawal of low creditworthy borrowers from the potential recipients of unsolicited ratings explains the positive selection of the unsolicited status.

The model integrates two elements of the ratings business that have not previously been studied jointly — unsolicited ratings and confidential ratings — and illustrates how the selection of borrowers into different solicitation groups may generate positive or negative average rating grade differences and differences in ex-post default rates without any strategic behavior from the rating agencies.

\subsection{The credit rating agencies business}

A rating conveys, in an alphanumerical grade, the probability that the borrower will fulfil its repayment obligations in a timely fashion. Borrowers approach the rating agency in hopes of a positive evaluation, which may allow them to sell their debt on the credit market at a lower price. They are charged a fee regardless of the outcome of the evaluation. ${ }^{\mathrm{b}}$

Another option available to the borrowers is to ask for a confidential preliminary rating, a nonbinding forecast of the rating they would receive if they were to solicit an official rating. The two largest rating agencies, S\&P and Moody's, offer this service as part of their ancillary services. ${ }^{\mathrm{c}}$ Preliminary ratings are confidential, and the borrower may decide whether to proceed with the issuance of a final rating.

Borrowers may also receive an unsolicited rating without their solicitation nor a payment of a fee. All three big rating agencies have been involved in issuing unsolicited ratings. S\&P started issuing unsolicited ratings in 1996 as a response in part to Moody's rating practices (Langohr \& Langohr 2008). Fitch followed their lead in 2001. The CRAs argue that they release unrequested opinions when there is notable interest among investors to justify public disclosure. Another reason, according to Byoun \& Shin (2002), is that "unsolicited ratings are considered a means of raising a rating agency's profile in particular countries, that is, rating agencies provide unsolicited ratings to investors in an attempt to gain a competitive advantage over those who do not assign an unsolicited rating." As an agency becomes known, it is more likely to be approached by clients requesting its services. Even if a rating agency is well known, producing more ratings or more recent ratings may be a way to let the market know about their technology and advertise their accuracy. A standard rating is easier for lenders to interpret and is more helpful in attracting funds. For instance, in response to a European Securities and Markets Authority (ESMA) call for evidence on the "Competition, choice and conflicts of interest in the credit rating

\footnotetext{
b According to the 2013 amendment to the EU legislation on credit rating agencies, "fees charged for credit rating services shall not depend on the level of the credit rating issued by the CRA or on any other result or outcome of the work performed" (Annex I Sec. B 3c through Article 6(2) of the Regulation (EU) No. 462/ 2013 of the European Parliament and of the Council of 21 May 2013 amending Regulation (EC) No. 1060/ 2009 on CRAs).

cMoody's Rating Assessment Service was launched in 2000. They charge 75000 Euros for an unofficial rating (The Economist 2001). S\&P also offers a similar service called the Ratings Evaluation System.
} 
industry" FCE Bank plc indicated that "in order to protect and provide confidence to our investors, we tend to select the market accepted CRAs." (ESMA, 2015).

Unsolicited ratings have been under the scrutiny of the American Justice Department, which started an antitrust investigation in 1996 suspecting that Moody's practice of issuing unsolicited ratings could be a strategy to push borrowers into soliciting more favorable official ratings. Three years later, it was abandoned without further action being taken.

\subsection{Evidence of upward bias in unsolicited ratings}

Figure 1 reports the distribution of the rating levels separately for solicited and unsolicited ratings across different sectors (nonfinancial, financial and government). Alphanumerical grades have been transformed into a numerical scale with higher numbers indicating a higher rating level. The discrepancy between solicited and unsolicited ratings differs in each sector. The whole distribution of unsolicited ratings is skewed towards lower levels in the financial sector with respect to solicited ratings whereas, in the government sector, the opposite is true. In the nonfinancial sector (comprising communications, consumer discretionary, consumer staples, energy, health care, industrials, materials, technology and utilities) the evidence is mixed: the unsolicited ratings distribution is more compressed although,

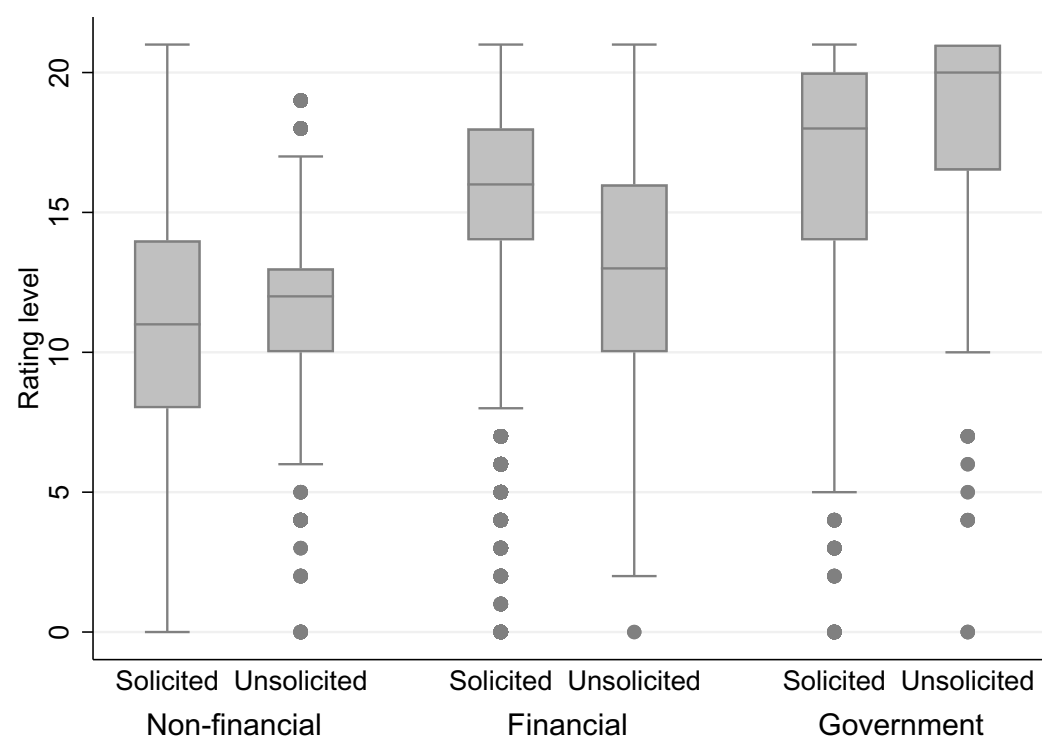

Note: Rating level is the long-term foreign currency issuer ratings by S\&P between 1996 and 2016. Ratings have been transformed into a numerical scale from 0 (D/SD) to 21 (AAA). Unsolicited ratings are those marked 'pi' or ' $u$ ', and all other ratings are solicited. The box represents the values of the 75th, 50th and 25 th percentile from top to bottom, the whiskers are the maximum and minimum values and the dots are outside values. Source: Bloomberg.

Fig. 1. Distribution of the rating level by solicitation status and sector. 

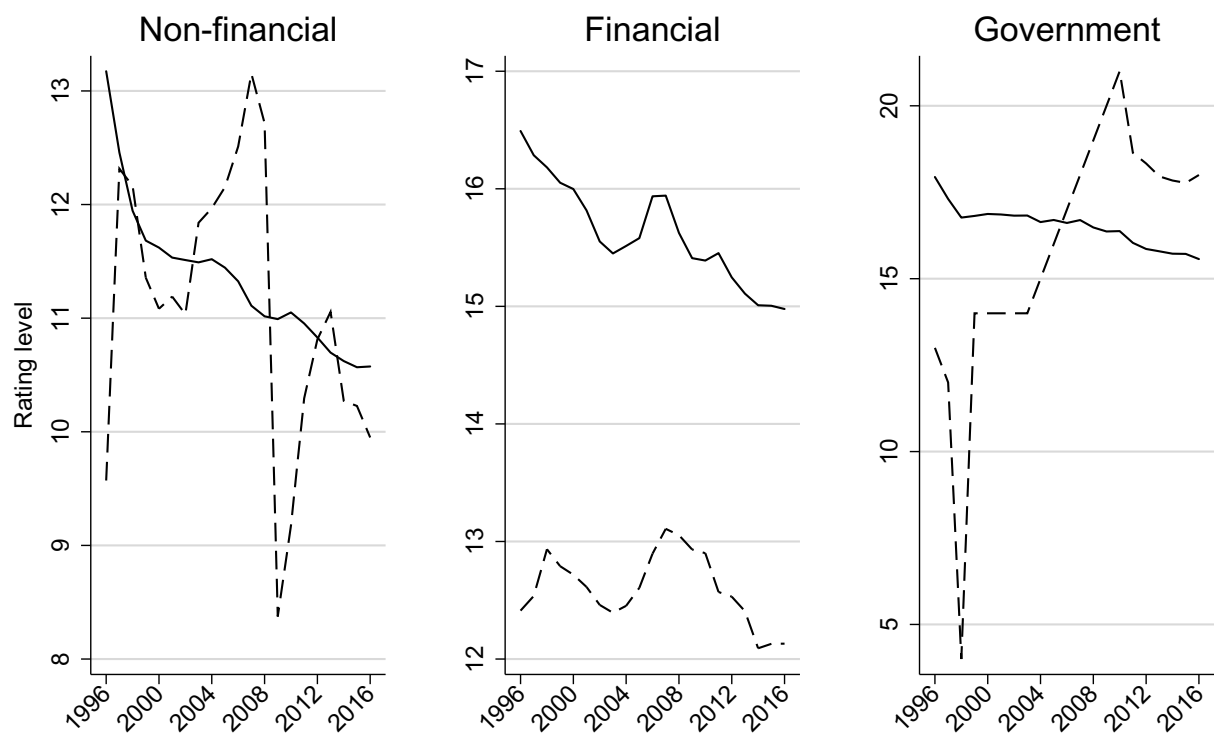

Solicited - - - Unsolicited

Note: Rating level is the long-term foreign currency issuer ratings by S\&P between 1996 and 2016. Ratings have been transformed into a numerical scale from 0 (D/SD) to 21 (AAA). Unsolicited ratings (dotted lines) are those marked 'pi' or ' $u$ ', and all other ratings are solicited (solid lines). Source: Bloomberg.

Fig. 2. Evolution of the average rating level by solicitation status and sector.

on average, the rating level is higher for unsolicited ratings than that of the solicited ratings.

If we focus on the evolution of the average ratings over time, as in Fig. 2, the pattern across different sectors is again very unequal. The financial sector has always displayed lower average unsolicited ratings and the discrepancy between solicited and unsolicited rating levels is also the largest; it amounts to 2.8 points average difference. If the mean solicited rating level for a financial firm in our sample is BBB+ the mean unsolicited rating level is instead $\mathrm{BB}+$, a full notch lower grade. In the government sector, we have to distinguish before and after 2011. In 2011, S\&P reclassified the solicitation status of several sovereign ratings to comply with European regulation. ${ }^{\mathrm{d}}$ Since then unsolicited ratings in the government sector have been on average 2.3 points higher than solicited ones and, if we consider the whole sample, they are on average 1.15 points higher. The nonfinancial sector exhibits large volatility of average unsolicited rating levels over time and they are sometimes higher and sometimes lower than their solicited counterparts.

d Article 10(5) of EU Regulation 1060/2009 addresses matters relating to the disclosure and presentation of credit ratings and requires, among other things, that unsolicited credit ratings be identified as such. 


\section{A Simple Model of Selection into Solicitation Status}

\subsection{Economic environment}

There are three agents in this economy: borrowers, lenders, and a CRA. Borrowers can be of two types: $i \in\{A, B\}$ with shares $\theta$ and $1-\theta$. Each borrower of type $i$ gets indebted for a fixed amount $D$. The gross return from production is $\tilde{R}=R$ with probability $\lambda_{i}$ and $\tilde{R}=r$ with probability $1-\lambda_{i}$, where $R>D>r>0$. Since the borrower has limited liability, type $i$ 's probability of default is $1-\lambda_{i}$, where $1 \geq \lambda_{A}>\lambda_{B}>0$.

Lenders do not know the borrower's type. They are risk neutral agents with discount factor $\beta$. Lenders compete on debt prices à la Bertrand, making zero expected profits. They charge a price $q$ for lending $D$, taking into account the expected probability of default, as specified later. For a pair $(q, D)$, the borrower's expected payoff equals $q D+\mathbb{E}_{i}\{\tilde{R}\}-\lambda_{i} D$, where $\mathbb{E}_{i}\{\tilde{R}\}:=\lambda_{i} R+\left(1-\lambda_{i}\right) r$.

In the economy, there is a CRA with costly access to private information about the borrower's type. This cost can be interpreted as the analyst's wage to study the data and produce a rating. The CRA incurs this cost every time they have to come up with a rating, regardless of whether they are compensated for it. By paying a cost $c$, the CRA receives the random signal $\sigma=\{H, L\}$ : if the country is of type A, the CRA receives the $H$ signal with probability 1 , while if the country is of type $\mathrm{B}$, the $H$ signal is received with probability $p<1$. The rating grade consists of a truthful report on the signal received and is denoted by $g \in\{H, L\}$.

The CRA provides three distinct products or services: solicited ratings, unsolicited ratings, and ancillary services. A solicited rating is requested by a borrower before issuing debt. The benefit of doing so is that a rating gives information to the market, and this may improve the debt price $q$ that lenders are willing to accept. The rating agency charges a fee $\phi$ for issuing solicited ratings. Before the borrower solicits a rating, the CRA can issue an unsolicited rating free of charge. The CRA benefits from unsolicited ratings, because they affect the fee that can be charged for a rating. I assume the following functional form for the fees: $\phi(D, \gamma)=\alpha_{1}+\alpha_{2} \gamma D$, where $\gamma$ denotes the fraction of unsolicited ratings. For $\alpha_{1}, \alpha_{2}>0$ fees are increasing in the amount of debt issued and in the fraction of unsolicited ratings issued. As stated above, unsolicited ratings have been viewed by some (Byoun \& Shin 2002, Langohr \& Langohr 2008) as a way to increase public visibility of the rating agency in a particular country or means of penetrating a specific market. This visibility is modeled in a reduced form as any action that allows the CRA to gain market power and charge higher fees for its solicited ratings.

The CRA also provides ancillary services for a fee $\chi$. Ancillary services give the borrower the opportunity to learn about the CRA's private signal and to veto the

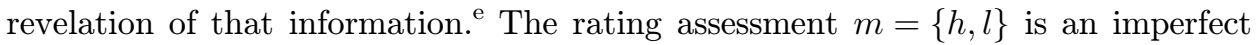

e Ancillary services can play several roles. For instance, they can reduce uncertainty about the outcome of the rating process for the borrowers or improve the transmission of information between the borrower and the rating agency. In addition, CRAs have started to guarantee confidentiality as an essential element in some of these services. 


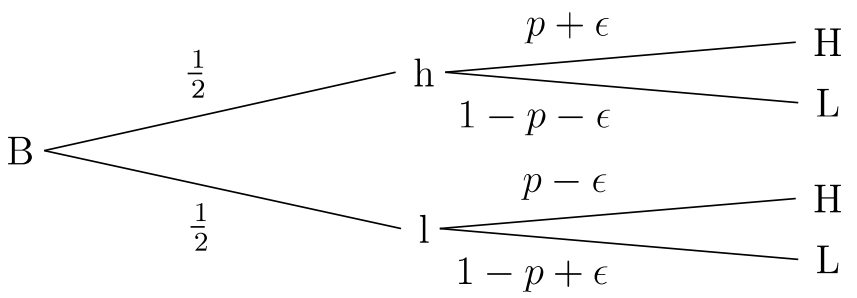

Fig. 3. Ancillary services assessment.

forecast of the rating signal $g$, and it is summarized in Fig. 3. An assessment $m=h$ is received with probability $\frac{1}{2}$ and $m=l$ with probability $\frac{1}{2}$. Conditional on receiving a positive assessment, type $\mathrm{B}$ receives a rating grade $H$ with probability $p+\epsilon$, and $L$ with the complementary probability $1-p-\epsilon$, whereas conditional on a negative assessment a rating grade $H$ is given with probability $p-\epsilon$ and $L$ with probability $1-p+\epsilon$. There is no uncertainty about a type A rating; it receives $H$ with probability 1 . Assume $\epsilon>0$ and $\epsilon<1-p$. These probabilities can be seen as posteriors and the technology of information acquisition is the same in both cases. Additionally, in the ancillary services contract, the agency commits that it will not issue an unsolicited rating if the borrower does not solicit one.

Assume that a fraction $\xi$ of borrowers does not enter the game; they access the market issuing unrated debt. This assumption guarantees that the $g=L$ rating, which is fully revealing of a $B$ type, is perceived to be worse than no rating $g=0$. Having a low rating or being downgraded is known to have an effect in the price of debt. It is reasonable for borrowers to expect that the market will judge them more harshly if they have been given a bad rating than if they have no rating at all. In the absence of bad news, borrowers can expect lenders to have some uncertainty about their credit standing. As unrated countries are a pool of different borrowers that do not access rating services, being unrated could be perceived as better than having a low rating. ${ }^{\mathrm{f}}$

The timing of the model is as follows:

(1) In stage $t=0$, the borrower decides whether to buy ancillary services at cost $\chi$. I denote this decision by $a \in\{0,1\}$.

(2) If the borrower is a client of ancillary services, in stage $t=1$, the borrower receives a nonbinding assessment of the rating grade, which can be $m=h$ or $m=l$. In stage $t=2$, borrowers choose whether to solicit and pay the fee $\phi(D, \gamma)$ for a rating: $s=\{0,1\}$. The notation for an unrated borrower is $g=0$.

(3) If the borrower is not a client of ancillary services, in stage $t=1$, the rating agency may issue an unsolicited rating. $\gamma \in[0,1]$ represents the fraction of unsolicited ratings issued. After deciding to issue an unsolicited rating, the signal

${ }^{f}$ As a matter of fact, a small but growing number of borrowers has decided to issue debt in the international debt market without a rating. They have accounted for about $10 \%$ of the European corporate bond market in recent years and are usually classified as investment, or near-investment grade (Bolger \& Wigglesworth 2014). 
$\sigma=\{H, L\}$ is received. In stage $t=2$, borrowers that did not receive an unsolicited rating have the option to solicit one, $s=\{0,1\}$. Note that a borrower cannot have both a solicited and an unsolicited rating.

Lenders observe the choices of the borrower and those of the rating agency, except for ancillary services, which are kept confidential between the borrower and the CRA. Thus, the borrower can have one of the two rating grades, $g=H$ or $g=L$, or none, $g=0$.

\subsection{CRA problem}

The CRA takes two actions: in $t=1$ it decides the fraction $\gamma$ of unsolicited ratings to nonclients of ancillary services, ${ }^{\mathrm{g}}$ and in $t=2$ it issues a solicited rating if it has been asked for one. The truth-telling assumption implies that the grade report will be either the signal the CRA received or none. I denote the rating grade report $g(a, u, s, \sigma)$, where the first element corresponds to the choice of ancillary services, the second represents the existence of an unsolicited rating, the third represents a solicited rating, and the last element is the signal of the creditworthiness of the borrower available to the CRA. Depending on those elements, the rule for assigning a rating grade is as follows:

$$
\begin{array}{ll}
g^{*}(1,0,1, \sigma)=\sigma, & g^{*}(1,0,0, \sigma)=0, \\
g^{*}(0,0,1, \sigma)=\sigma, & g^{*}(0,1,0, \sigma)=\sigma,
\end{array}
$$

and

$$
g^{*}(0,0,0, \sigma)=0 .
$$

When the borrower is a client of ancillary services, $a=1$, it may or may not request a rating, in which case it will not receive an unsolicited rating. If the borrower is not a client, $a=0$, it may request a rating and, if not, it may receive an unsolicited rating or it may also be unrated.

In $t=1$ the CRA problem is as follows:

$$
\max _{\gamma}-\gamma c+\left[(1-\gamma) f^{*}(\gamma)(\phi(D, \gamma)-c)\right]
$$

where $f^{*}(\gamma)$ is the fraction of borrowers that solicit a rating in equilibrium. The CRA chooses the proportion of unsolicited ratings taking into account that each rating has a cost $c$ today and it also has an effect in the next stage. On one hand, it crowds out solicited ratings, as a borrower cannot have both a solicited and unsolicited rating, hence only $1-\gamma$ borrowers are susceptible to solicit a rating afterwards; on the other hand, it increases the fees that can be charged for those solicited ratings.

g Recall that clients of ancillary services do not receive unsolicited ratings. 


\subsection{Lenders' problem}

Lenders lend the amount $q D$ to the borrower and receive $D$ if there is no default. In case of default, there is no partial repayment. The lender profit function is

$$
\Pi=-q D+\beta\left[\mu \lambda_{A} D+(1-\mu) \lambda_{B} D\right]
$$

where $\mu=\mu(s, g)$ are the lenders' beliefs that the borrower is of type A, given $s, g$. Beliefs depend on what the lender observes about the borrower's creditworthiness: the solicitation status and the rating grade. As a result of imposing the zero-profit condition, the price function satisfies as follows:

$$
q(\mu)=\beta\left[\mu \lambda_{A}+(1-\mu) \lambda_{B}\right]
$$

The value $\mu(0,0)$ represents the lenders' beliefs when they see no rating for a borrower. The values $\mu(0, H)$ and $\mu(0, L)$ represent what lenders believe about an unsolicited rating of $H$ or $L$, respectively.

\subsection{Borrower's problem}

The borrower faces two problems: whether to buy ancillary services at $t=0$ and whether to solicit a rating at $t=2$. The borrower's payoff, depending on its rating, is as follows:

- If the borrower buys ancillary services and solicits a rating: $q(\mu) D+\lambda_{i}(R-$ $D)+\left(1-\lambda_{i}\right) r-\phi(D, \gamma)-\chi$, where the first term is the amount of borrowing at price $q(\mu)=q(1, g)$, the second and third terms are the net revenues weighted by the repayment probabilities, and the last two terms are the fees for solicitation and ancillary services, respectively.

- If the borrower solicits a rating but does not buy ancillary services, it saves on the amount of ancillary fees: $q(1, g) D+\lambda_{i}(R-D)+\left(1-\lambda_{i}\right) r-\phi(D, \gamma)$.

- A borrower that does not buy ancillary services may receive an unsolicited rating with an associated payoff of $q(0, g) D+\lambda_{i}(R-D)+\left(1-\lambda_{i}\right) r$, where the price of debt is $q(0, g)$ and the borrower does not incur any fees.

- Finally, if the borrower is unrated the payoff equals $q(0,0) D+\lambda_{i}(R-D)+(1-$ $\left.\lambda_{i}\right) r$ if it did not buy ancillary services or $q(0,0) D+\lambda_{i}(R-D)+\left(1-\lambda_{i}\right) r-\chi$ if it did.

\subsection{Equilibrium}

I use the Perfect Bayesian Equilibrium concept to solve for the equilibrium outcome of the credit market with a CRA that issues solicited and unsolicited ratings and provides confidential ancillary services. First, I define the Perfect Bayesian Equilibrium in the context of this model. In Sec. 2.6, I apply it to solve the model without ancillary services. In Sec. 2.7, I solve for the full model. 
Definition 2.1. Given the CRA rule of $g^{*}(a, u, s, \sigma)$, symmetric equilibrium is a fraction $\gamma^{*}$, a strategy for the borrower:

$$
\left\{a^{*}, s^{*}\right\}:\{A, B\} \rightarrow\{0,1\} \times\{0,1\},
$$

where $a^{*}(i)$ is the choice of ancillary services and $s^{*}(i, a(i))$ is the rating solicitation, a strategy for the lender on the debt price $q^{*}(s, g):\{0,1\} \times\{H, L, 0\} \rightarrow \mathbb{R}_{+}$and a system of beliefs $\mu^{*}(s, g):\{0,1\} \times\{H, L, 0\} \rightarrow[0,1]$ about the borrower being type A, such that:

- $\gamma^{*}$ maximizes the CRA profit function (2.4) and the fraction of borrowers that solicit a rating $f^{*}(\gamma)$ is consistent with the borrower's strategy.

- The strategy profile is sequentially rational given the beliefs and $\gamma^{*}$.

- The beliefs are consistent with Bayes' rule whenever possible.

\subsection{Solving without ancillary services}

Let us first solve the model without ancillary services. The game starts at $t=1$. All the other modeling assumptions remain the same.

Let $\phi\left(D, \theta, \xi, \lambda_{A}, \lambda_{B}, \alpha_{1}, \alpha_{2}, c\right)$ be within $(\phi, \overline{\bar{\phi}})$. These threshold levels, as a function of parameters, are imposed to ensure that fees are not so high that no type solicits a ratings nor so low that both types do. ${ }^{\text {h }}$

Proposition 2.1. A rule of $g^{*}(u, s, \sigma): g^{*}(0,1, \sigma)=\sigma, g^{*}(1,0, \sigma)=\sigma \quad$ and $g^{*}(0,0, \sigma)=0$, the strategies $s^{*}(A)=1, s^{*}(B)=0, q^{*}(\mu)=\mu \lambda_{A}+(1-\mu) \lambda_{B}$ and $\gamma^{*}$ $=\frac{(1-\theta) c+\theta \alpha_{1}}{-2 \theta \alpha_{2} D}+\frac{1}{2}$ constitute an equilibrium of the model without ancillary services given the beliefs $\mu(s, g): \mu(s, L)=0 \forall s, \mu(1, H)=1$,

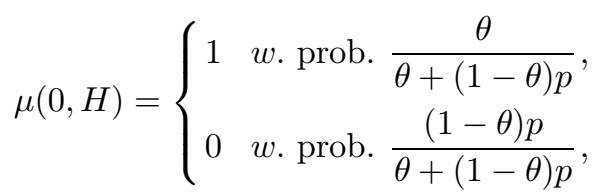

$\mathrm{h}$ The threshold levels are:

$$
\begin{aligned}
\overline{\bar{\phi}}:= & \beta\left(1-\frac{\theta \xi}{\theta \xi+(1-\theta)\left(1+\left(\frac{(1-\theta) c+\theta \alpha_{1}}{-2 \theta \alpha_{2} D}+\frac{1}{2}\right)(\xi-1)\right)}\right) \lambda_{A} D \\
& -\beta \frac{(1-\theta)\left(1+\left(\frac{(1-\theta) c+\theta \alpha_{1}}{-2 \theta \alpha_{2} D}+\frac{1}{2}\right)(\xi-1)\right)}{\theta \xi+(1-\theta)\left(1+\left(\frac{(1-\theta) c+\theta \alpha_{1}}{-2 \theta \alpha_{2} D}+\frac{1}{2}\right)(\xi-1)\right)} \lambda_{B} D \text { and } \\
\underline{\underline{\phi}:=} & \beta\left(p-\frac{\theta \xi}{\theta \xi+(1-\theta)\left(1+\left(\frac{(1-\theta) c+\theta \alpha_{1}}{-2 \theta \alpha_{2} D}+\frac{1}{2}\right)(\xi-1)\right)}\right) \lambda_{A} D \\
& +\beta\left((1-p)-\frac{(1-\theta)\left(1+\left(\frac{(1-\theta) c+\theta \alpha_{1}}{-2 \theta \alpha_{2} D}+\frac{1}{2}\right)(\xi-1)\right)}{\theta \xi+(1-\theta)\left(1+\left(\frac{(1-\theta) c+\theta \alpha_{1}}{-2 \theta \alpha_{2} D}+\frac{1}{2}\right)(\xi-1)\right)}\right) \lambda_{B} D .
\end{aligned}
$$


and

$$
\mu(0,0)=\left\{\begin{array}{ccc}
1 & w \cdot \text { prob. } & \frac{\theta \xi}{\theta \xi+(1-\theta)(1+\gamma(\xi-1))} \\
0 & w \cdot \text { prob. } & \frac{(1-\theta)(1+\gamma(\xi-1))}{\theta \xi+(1-\theta)(1+\gamma(\xi-1))}
\end{array}\right.
$$

The CRA assigns a proportion $\gamma^{*}$ of unsolicited ratings to both type A and type B borrowers in order to maximize its profit function (2.4) in $t=1$ :

$$
\max _{\gamma}-\gamma c+(1-\gamma) \theta[\phi(D, \gamma)-c]
$$

Substituting the functional form of $\phi(D, \gamma)$ and solving the maximization problem, we obtain the first-order condition:

$$
-c-\theta\left(\alpha_{1}+\alpha_{2} \gamma D\right)+\theta(1-\gamma) \alpha_{2} D+\theta c=0 .
$$

Rearranging, we find an expression for the optimal fraction of unsolicited ratings that the CRA issues:

$$
\gamma^{*}=\frac{(1-\theta) c+\theta \alpha_{1}}{-2 \theta \alpha_{2} D}+\frac{1}{2} .
$$

Since $\alpha_{1}, \alpha_{2}$, c and $\theta$ are nonnegative, $\gamma^{*}$ is increasing in the amount of debt. $\gamma^{*}$ also represents the probability that a nonclient of ancillary services will get an unsolicited rating.

Type A prefers to solicit a rating rather than remain unrated if they are not given an unsolicited rating, while type B does not. In equilibrium, $\phi$ has to remain within upper and lower bounds, which depend on $D, \gamma^{*}, \theta, \lambda_{A}$, and $\lambda_{B}$. A fee that is too high would discourage even the best borrowers from asking for a rating, and a fee that is too low would encourage the worst borrowers to try to obtain a high rating with probability $p$.

Type A can have either a solicited or unsolicited $H$ rating, and a fraction $\xi$ is unrated by assumption. If type A were allowed to solicit a rating after an unsolicited rating, they may choose to do so, because the price of debt is better for solicited ratings for the same $\mathrm{H}$ grade. We simplify away from this possibility, but this behavior is something we might observe. Type B can have an $H$ unsolicited rating, $L$ unsolicited rating, or no rating. There are no grade $\mathrm{L}$ solicited ratings. Thus, unsolicited ratings have lower grades on average.

Type A knows that it is more likely to receive an $H$ rating, so it has an incentive to pay the fee for a solicited rating. Type B, on the contrary, has a lower probability $p$ of receiving an $H$ rating and a high probability of receiving an $L$ rating, which bears a higher risk premium than no rating. The fact that higher quality borrowers are more inclined to get rated is a well-known result in the literature (Lizzeri 1999, Mathis et al. 2009, Fulghieri et al. 2014). The novelty here is that type B borrowers stand to lose more on average from getting an unsolicited rating than type A borrowers. ${ }^{i}$

${ }^{i}$ Actually, type A borrowers benefit from truthful unsolicited ratings, because they save on solicitation fees. 
As long as there are no ancillary services, this heterogeneous effect plays no role, because there is nothing a Type B borrower can do about it. This changes in Sec. 2.7.

\subsection{Introducing ancillary services}

Let $\phi\left(D, \theta, \xi, \lambda_{A}, \lambda_{B}, \alpha_{1}, \alpha_{2}, c\right)$ be within $(\underline{\phi}, \bar{\phi})$, where the threshold levels, as a function of parameters, restrict the range of admissible fees. ${ }^{j}$

Proposition 2.2 (Positive selection). Assume the following condition on parameters:

$$
\begin{aligned}
\xi< & \frac{2 \alpha_{2} D(1-\theta) \beta G\left(\theta, \xi, \lambda_{A}, \lambda_{B}\right)-4\left[(1-\theta)+\theta \alpha_{1}\right] \beta G\left(\theta, \xi, \lambda_{A}, \lambda_{B}\right)}{4 \theta \alpha_{2} D} \\
& -\frac{2(1-\theta) c \alpha_{2} D+(\theta+1)\left(\alpha_{2} D\right)^{2}}{4 \theta \alpha_{2} D}
\end{aligned}
$$

where $G\left(\theta, \xi, \lambda_{A}, \lambda_{B}\right)=\frac{2 \theta \xi \lambda_{A}+(1-\theta)(\xi+1) \lambda_{B}}{2 \theta \xi+(1-\theta)(\xi+1)}$. For $g^{*}(a, u, s, \sigma)$ given by Eqs. (2.1)-(2.3), the strategies $a^{*}(A)=0, a^{*}(B)=1, s^{*}(A, 0)=1, s^{*}(B, 0)=0, s^{*}(A, 1)=1$, $s^{*}(B, 1)=1$ if $m=h$ and 0 if $m=l, q^{*}(\mu)=\mu \lambda_{A}+(1-\mu) \lambda_{B}$ and $\gamma^{*}$ that solves problem (2.4) constitute an equilibrium of the model given the following beliefs: $\mu(0, H)=1, \mu(s, L)=0 \forall s=\{0,1\}$,

$$
\mu(1, H)=\left\{\begin{array}{ccc}
1 & w \cdot \text { prob. } & \frac{2 \theta(1-\gamma)}{2 \theta(1-\gamma)+(1-\theta)(p+\epsilon)}, \\
0 & w . \text { prob. } & \frac{(1-\theta)(p+\epsilon)}{2 \theta(1-\gamma)+(1-\theta)(p+\epsilon)}
\end{array}\right.
$$

and

$$
\mu(0,0)=\left\{\begin{array}{ccc}
1 & w \cdot \text { prob. } & \frac{2 \theta \xi}{2 \theta \xi+(1-\theta)(\xi+1)} \\
0 & w \cdot \text { prob. } & \frac{(1-\theta)(\xi+1)}{2 \theta \xi+(1-\theta)(\xi+1)}
\end{array}\right.
$$

j The threshold levels are:

$$
\begin{aligned}
\bar{\phi}:= & \beta\left[(p+\epsilon) \frac{2 \theta(1-\xi)\left(1-\left(\frac{(1-\theta) c+\theta \alpha_{1}}{-2 \theta \alpha_{2} D}+\frac{1}{2}\left(\frac{1}{2}+\frac{1}{2 \theta}\right)\right)\right) \lambda_{A}+(1-\theta)(1-\xi)(p+\epsilon) \lambda_{B}}{(1-\xi)\left[2 \theta\left(1-\left(\frac{(1-\theta) c+\theta \alpha_{1}}{-2 \theta \alpha_{2} D}+\frac{1}{2}\left(\frac{1}{2}+\frac{1}{2 \theta}\right)\right)\right)+(1-\theta)(p+\epsilon)\right]}\right. \\
& \left.+(1-p-\epsilon) \lambda_{B}-\frac{2 \theta \xi \lambda_{A}+(1-\theta)(\xi+1) \lambda_{B}}{2 \theta \xi+(1-\theta)(\xi+1)}\right] D \text { and } \\
\underline{\phi}:= & \beta\left[p \frac{2 \theta(1-\xi)\left(1-\left(\frac{(1-\theta) c+\theta \alpha_{1}}{-2 \theta \alpha_{2} D}+\frac{1}{2}\left(\frac{1}{2}+\frac{1}{2 \theta}\right)\right)\right) \lambda_{A}+(1-\theta)(1-\xi)(p+\epsilon) \lambda_{B}}{(1-\xi)\left[2 \theta\left(1-\left(1-\left(\frac{(1-\theta) c+\theta \alpha_{1}}{-2 \theta \alpha_{2} D}+\frac{1}{2}\left(\frac{1}{2}+\frac{1}{2 \theta}\right)\right)\right)\right)+(1-\theta)(p+\epsilon)\right]}\right. \\
& \left.+(1-p) \lambda_{B}-\frac{2 \theta \xi \lambda_{A}+(1-\theta)(\xi+1) \lambda_{B}}{2 \theta \xi+(1-\theta)(\xi+1)}\right] D .
\end{aligned}
$$


(Negative selection). Assume condition (2.9) is not satisfied. For $g^{*}(a, u, s, \sigma)$ given by Eqs. (2.1)-(2.3), the strategies $a^{*}(A)=0, a^{*}(B)=0, s^{*}(A, 0)=1, s^{*}(B, 0)=$ $0, s^{*}(A, 1)=1, s^{*}(B, 1)=1$ if $m=h$ and 0 if $m=l, q^{*}(\mu)=\mu \lambda_{A}+(1-\mu) \lambda_{B}$ and $\gamma^{*}$ that solves problem (2.4) constitute an equilibrium of the model given the following beliefs: $\mu(s, g): \mu(s, L)=0 \forall s=\{0,1\}, \mu(1, H)=1$,

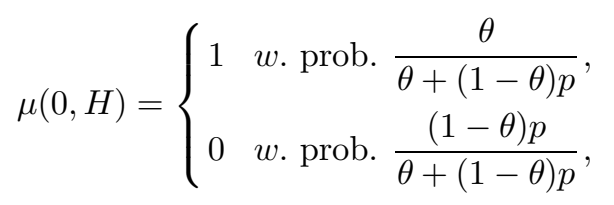

and

$$
\mu(0,0)=\left\{\begin{array}{ccc}
1 & w \cdot \text { prob. } & \frac{\theta \xi}{\theta \xi+(1-\theta)(1+\gamma(\xi-1))} \\
0 & w . \text { prob. } \frac{(1-\theta)(1+\gamma(\xi-1))}{\theta \xi+(1-\theta)(1+\gamma(\xi-1))}
\end{array}\right.
$$

In the equilibrium with positive selection described above, the CRA assigns a proportion $\gamma^{*}$ of unsolicited ratings, which are grade $\mathrm{H}$ and go to type $\mathrm{A}$ borrowers. Type B borrowers enter a contract for ancillary services and avoid receiving unsolicited ratings. They can either have a solicited rating (which can be $H$ or $L$ ), after having observed the assessment $m=h$, or no rating, after having observed the assessment $m=l$. A fraction $\xi$ of borrowers is unrated by assumption. Type A borrowers that are not exogenously unrated or that have not received an unsolicited rating solicit and receive an $H$ rating. There are no grade $L$ unsolicited ratings, as type B borrowers that would be subject to receiving such a rating prefer to pay for ancillary services and veto that possibility. In equilibrium, type A borrowers prefer to solicit a rating, whether they are clients of ancillary services or not. Their incentives to solicit are high, because the probability of getting a high rating is good as long as the price of ratings is sufficiently low. Type B borrowers, on the contrary, prefer not to solicit a rating unless they are given a strong signal that the rating will be high in the form of a positive assessment. Otherwise, the fees are too high with respect to the probability $p$ of being given an $H$ rating.

Taking into account the solicitation choices of the borrowers, the CRA problem (2.4) from the previous period can be rewritten as follows:

$$
\max _{\gamma}-\gamma c+(1-\gamma) \theta[\phi(D, \gamma)-c]+\frac{1}{2}(1-\theta)[\phi(D, \gamma)-c]
$$

Plugging in the functional form of $\phi(D, \gamma)$ and solving for $\gamma$ :

$$
\gamma^{*}=\frac{(1-\theta) c+\theta \alpha_{1}}{-2 \theta \alpha_{2} D}+\frac{1}{2}\left(\frac{1}{2}+\frac{1}{2 \theta}\right),
$$

where the first two terms coincide with the expression for the optimal fraction of unsolicited ratings in the model without ancillary services and the term in 
parenthesis, which is $>1$ for $0<\theta<1$, represents the additional incentive to issue unsolicited ratings due to the gains coming from the clients of ancillary services.

The condition (2.9) can be reformulated as

$$
\gamma>\bar{\gamma}:=\frac{\beta G\left(\theta, \xi, \lambda_{A}, \lambda_{B}\right)+\frac{\alpha_{1}}{2}+\chi}{2 \beta G\left(\theta, \xi, \lambda_{A}, \lambda_{B}\right)-\alpha_{2} D},
$$

where $G\left(\theta, \xi, \lambda_{A}, \lambda_{B}\right)=\frac{2 \theta \xi \lambda_{A}+(1-\theta)(\xi+1) \lambda_{B}}{2 \theta \xi+(1-\theta)(\xi+1)}$. This guarantees that $a^{*}(B)=1$. For a high enough $\gamma^{*}$, type B prefers to buy ancillary services for a fee $\chi$ and obtain a rating $H$ with probability $p$ and no rating $g=0$ with probability $1-p$ than getting an unsolicited $H$ rating with probability $\gamma p$ and risking an $L$ rating with probability $\gamma(1-p)$. The fact that $a^{*}(A)=0$ is always true, ${ }^{\mathrm{k}}$ because type $\mathrm{A}$ always receives an $H$ rating and ancillary services only represent a cost.

In this equilibrium, all unsolicited ratings are grade $\mathrm{H}$, whereas of the total $\theta(1-\gamma)+(1-\theta) \frac{1}{2}$ solicited ratings, $\theta(1-\gamma)+(1-\theta) \frac{1}{2}(p+\epsilon)$ are grade $\mathrm{H}$ and the rest are grade $\mathrm{L}$. If we translate grades into a numerical scale and assign 1 to grade $\mathrm{H}$ and 0 to grade $\mathrm{L}$, we obtain that the average unsolicited rating is higher than the average solicited rating:

$$
1>\frac{\theta(1-\gamma)+(1-\theta) \frac{1}{2}(p+\epsilon)}{\theta(1-\gamma)+(1-\theta) \frac{1}{2}} .
$$

Henceforth, there is a positive selection of creditworthy borrowers in unsolicited ratings.

Since unsolicited $H$ ratings are assigned only to A types, they are fully revealing of the high-quality type. But because solicited $H$ ratings can be assigned to $\mathrm{A}$ and $\mathrm{B}$ types, we expect to see a market discount in the price of debt of high unsolicited ratings.

On the contrary, when condition (2.9) is not satisfied, $\gamma^{*}<\bar{\gamma}$ and type B does not choose ancillary services, the equilibrium outcome is similar to that which is described in the solution to the model without ancillary services. A formal description of the equilibrium can be found in the second part of Proposition 2.2. In this case, ancillary services do not exist in equilibrium. All grade $\mathrm{H}$ solicited ratings are assigned to type $\mathrm{A}$ borrowers, whereas grade $\mathrm{H}$ unsolicited ratings can be given to type A or B with different probabilities. Grade L unsolicited ratings are assigned to type B borrowers. Finally, unrated borrowers can be either type A or B.

In this equilibrium, unsolicited ratings can be grade $\mathrm{H}, \theta \gamma+(1-\theta) \gamma p$ out of $\theta \gamma+(1-\theta) \gamma$, and the rest are grade $\mathrm{L}$. If we translate grades into a numerical scale and assign 1 to grade $\mathrm{H}$ and 0 to grade $\mathrm{L}$, we obtain that the average unsolicited rating is lower than the average solicited rating:

$$
\frac{\theta \gamma+(1-\theta) \gamma p}{\theta \gamma+(1-\theta) \gamma}<1
$$

due to a negative selection of creditworthy borrowers in unsolicited ratings.

${ }^{\mathrm{k}}$ For $a^{*}(A)=0: \gamma q(0, H) D+(1-\gamma)[q(1, H) D-\phi(\gamma, D)]>\frac{1}{2} q(1, H) D+\frac{1}{2} q(1, H) D-\phi(\gamma, D)-\chi$. Since $q(0, H)>q(1, H)$, the statement is always true. 
The trade-offs that determine the sign of selection are the profitability of a market (in terms of visibility or higher fees), which makes it more attractive to issue unsolicited ratings, and the return of remaining unrated as opposed to receiving a bad rating for the less creditworthy borrower.

\section{Empirical analysis}

\subsection{Dataset and definition of the variables}

The dataset contains end-of-year long-term foreign currency ratings for all entities with issuer ratings by S\&P. Long-term issuer ratings are defined as "a forwardlooking opinion about an obligor's overall creditworthiness." (Standard\&Poor's 2017). I obtained the data from Bloomberg by collecting all rating actions (including rating assignments, upgrades, downgrades, confirmations, rating outlook, and rating watch changes) from 1950 to the present. Bloomberg reports only rating actions, not the outstanding rating, hence if a rating existed before 1950 and has not been revised for confirmation or changed ever since it would not be included in the database. This is a very unlikely situation, as the rating agencies revise their ratings periodically to keep them up to date. Since S\&P did not report the solicitation status of their issuer's ratings consistently before 1996, I focus on that year onwards. In constructing the database I assumed that if no rating action takes place the previously assigned rating is still valid. The final database has 164.020 ratings and almost 18.000 distinct borrowers.

Following the literature, I transformed the ratings into a numerical scale from 0 (D/SD) to 21 (AAA). ${ }^{1}$ Rating modifiers (indicated by a plus or minus sign appended to the alphanumerical grade) are represented by a 1 point change in the scale. Credit rating watch is classified separately and it is used as a control in some specifications. Ratings are defined as unsolicited if S\&P reports them as "pi" or " $u$ "; otherwise they are classified as solicited. Solicitation is captured in a dummy variable that takes the value of 1 if the rating is unsolicited and 0 if it is solicited.

Table 1 reports the number of ratings in the final dataset by sector. Instead, pooling all sectors together and looking at the difference across regions, Africa $(25.1 \%)$, Asia $(15.9 \%)$, and North-America $(8.1 \%)$ are the regions where most unsolicited ratings are assigned. In particular, from all unsolicited ratings, $55 \%$ are in the US, $9.28 \%$ in Japan, and, within Europe, $3.81 \%$ are in the UK, $3.38 \%$ are in Germany, $1.75 \%$ are in France, and $1.30 \%$ are in Italy.

I merge ratings data with firm characteristics from Datastream. This includes earnings before interest and taxes plus depreciation (EBITD), number of employees, interest expense, net debt, net revenues, stock prices, total assets, total debt, debt over common equity, and debt over capital, with country economic fundamentals from the World Economic Outlook April 2017 and long-term sovereign bond yields

${ }^{1} \mathrm{~S} \& \mathrm{P}$ rating scale is, in decreasing order of credit quality: AAA, AA, A, BBB, BB, B, CCC, CC, C, D. 
Table 1. Number of S\&P issuer ratings by solicitation status and sector.

\begin{tabular}{|c|c|c|c|}
\hline Sector & Solicited & Unsolicited & Total \\
\hline Communications & $\begin{array}{r}8701 \\
\quad(99.7)\end{array}$ & $\begin{array}{l}27 \\
(0.3)\end{array}$ & $\begin{array}{l}8728 \\
(100.0)\end{array}$ \\
\hline Consumer discretionary & $\begin{array}{r}14804 \\
(96.9)\end{array}$ & $\begin{array}{l}478 \\
(3.1)\end{array}$ & $\begin{array}{l}15282 \\
(100.0)\end{array}$ \\
\hline Consumer staples & $\begin{array}{l}5584 \\
\quad(98.2)\end{array}$ & $\begin{array}{l}100 \\
(1.8)\end{array}$ & $\begin{array}{l}5684 \\
(100.0)\end{array}$ \\
\hline Energy & $\begin{array}{c}7454 \\
(99.5)\end{array}$ & $\begin{array}{l}40 \\
(0.5)\end{array}$ & $\begin{array}{l}7494 \\
(100.0)\end{array}$ \\
\hline Finance & $\begin{array}{r}65745 \\
\quad(85.0)\end{array}$ & $\begin{array}{r}11574 \\
(15.0)\end{array}$ & $\begin{array}{l}77319 \\
\quad(100.0)\end{array}$ \\
\hline Government & $\begin{array}{l}8543 \\
(98.2)\end{array}$ & $\begin{array}{r}160 \\
(1.8)\end{array}$ & $\begin{array}{l}8703 \\
(100.0)\end{array}$ \\
\hline Health care & $\begin{array}{l}4596 \\
\quad(94.7)\end{array}$ & $\begin{array}{l}258 \\
(5.3)\end{array}$ & $\begin{array}{l}4854 \\
(100.0)\end{array}$ \\
\hline Industrials & $\begin{array}{l}9589 \\
\quad(98.3)\end{array}$ & $\begin{array}{l}166 \\
(1.7)\end{array}$ & $\begin{array}{l}9755 \\
(100.0)\end{array}$ \\
\hline Materials & $\begin{array}{l}8820 \\
\quad(97.7)\end{array}$ & $\begin{array}{l}209 \\
(2.3)\end{array}$ & $\begin{array}{l}9029 \\
(100.0)\end{array}$ \\
\hline Technology & $\begin{array}{l}4725 \\
\quad(98.8)\end{array}$ & $\begin{array}{l}56 \\
(1.2)\end{array}$ & $\begin{array}{l}4781 \\
(100.0)\end{array}$ \\
\hline Utilities & $\begin{array}{r}11711 \\
\quad(99.7)\end{array}$ & $\begin{array}{l}41 \\
(0.3)\end{array}$ & $\begin{array}{r}11752 \\
(100.0)\end{array}$ \\
\hline Total & $\begin{array}{r}150272 \\
(92.0)\end{array}$ & $\begin{array}{r}13109 \\
(8.0)\end{array}$ & $\begin{array}{r}163381 \\
(100.0)\end{array}$ \\
\hline
\end{tabular}

Notes: Ratings are long-term foreign currency issuer ratings issued by S\&P between 1996 and 2016. Unsolicited ratings are those marked "pi" or "u", and all other ratings are solicited. The first column reports the number of ratings with solicited status. The second column reports the number of ratings with unsolicited status. Percentages are in parenthesis.

Source: Bloomberg.

from the IMF's International Financial Statistics. The main summary statistics of firm level variables can be found in Table 2 .

\subsection{Measurement of selection in unsolicited ratings}

In this section, I investigate the presence of selection in unsolicited ratings across markets. My first objective is to understand whether the pattern in the difference between rating grades among solicitation groups can be attributed to selection. Secondly, I analyze the effects of selection on the market valuation of the borrower.

For most of the discussion, I focus on two sectors: the financial sector and the government sector. This is motivated by the fact that these sectors represent the majority of the unsolicited ratings in my sample. In addition, most of the empirical research on unsolicited ratings has been conducted in the financial sector (Gan 2004, 
Table 2. Summary statistics of the main variables.

\begin{tabular}{lccccc}
\hline & Count & Mean & sd & min & max \\
\hline Rating level & 164020 & 13.32722 & 4.420994 & 0 & 21 \\
Unsolicited dummy & 163801 & 0.08003 & 0.2713405 & 0 & 1 \\
Rating outlook & 164020 & -0.0233996 & 0.2172626 & -1 & 1 \\
Ebitd & 21068 & 0.1004432 & 1.052458 & -1.891937 & 55.31935 \\
Total assets & 22209 & 1.557312 & 12.55645 & $7.00 \mathrm{e}-08$ & 310.4507 \\
Total debt & 22114 & 0.4239711 & 3.474487 & 0 & 118.9319 \\
Debt over capital & 22101 & 44.81025 & 81.08229 & -7317.07 & 7864.71 \\
Stock price & 22027 & 2170.1 & 30623.31 & 0.0058 & 1805000 \\
Number employees & 20853 & 43564.87 & 90043.93 & 0 & 2300000 \\
Current account & 3901 & -3.000624 & 11.38962 & -112.926 & 63.835 \\
Revenue & 3800 & 29.5654 & 13.77025 & 0.637 & 160.191 \\
Expenditure & 3774 & 31.37485 & 13.30272 & 0 & 127.29 \\
Primary lending & 3601 & -0.2126482 & 6.321532 & -75.657 & 123.486 \\
Gross debt & 3558 & 56.31022 & 49.49276 & 0 & 789.833 \\
Population & 3927 & 34.59773 & 130.447 & 0.009 & 1382.71 \\
GDP & 3955 & 64863.83 & 492487.3 & 0.026 & 9433034 \\
Inflation & 3926 & 9.27222 & 73.63952 & -72.729 & 4146.01 \\
\hline
\end{tabular}

Notes: Rating level refers to the long-term foreign currency issuer ratings by S\&P between 1996 and 2016. Ratings have been transformed into a numerical scale from 0 (D/SD) to 21 (AAA). Unsolicited dummy is a dummy variable that takes the value of 1 if the rating is unsolicited and 0 if the rating is solicited. Rating outlook is a categorical variable that takes value of 1 if it is a positive outlook, -1 if it is negative, and 0 otherwise. Ebitd (earnings before interest and debt), total assets, total debt, and stock price are expressed in local currency. Debt over capital is the ratio of total debt to total capital. Number of employees is the number of workers in the firm. Current account, revenue, expenditure, primary lending, and gross debt are expressed as a percentage of GDP, population figures are expressed in millions, GDP is expressed in purchasing-power-parity dollars, and inflation is expressed as a percentage. The first column presents the number of observations, the second presents the mean value, the third presents the standard deviation, and the fourth and fifth columns present the minimum and maximum value, respectively.

Sources: Bloomberg, Datastream, and IMF.

Poon \& Firth 2005, Poon et al. 2009, Bannier et al. 2010, Van Roy 2013), particularly in the Asian market (Poon 2003, Poon \& Chan 2010, Byoun \& Shin 2012). For the sovereign analysis, I restrict the time dimension to 2011 onwards, as 2011 is the first year for which S\&P disclosed the solicitation status of a number of sovereign ratings in Europe and Asia (Standard \& Poor's, 2011a,b,c).

The main result derived from the model is that, unlike the strategic behavior that intends to punish the borrower, selection can work both ways. Depending on the parameters of the model, the characteristics of the prevailing equilibrium are such that we may find positive or negative differences in average ratings between borrowers with a solicited and unsolicited rating.

In order to investigate the effect of the solicitation status on the rating grade, I run the following regression:

$$
\text { Rating level }_{i, t}=\alpha+\beta \text { Unsolicited }_{i, t}+\gamma X_{i, t}+\lambda_{k}+\tau_{t}+\rho_{r}+\delta_{c}+e_{i, t},
$$


Table 3. Solicitation status effect on the rating level (pooled regression).

\begin{tabular}{lcccc}
\hline & $(1)$ & $(2)$ & $(3)$ & $(4)$ \\
& Rating level & Rating level & Rating level & Rating level \\
\hline Unsolicited dummy & $-2.396^{* * *}$ & $-2.368^{* * *}$ & $0.253^{* *}$ & $-0.912^{* *}$ \\
& $(0.0353)$ & $(0.0333)$ & $(0.114)$ & $(0.458)$ \\
Unsolicited $\times$ Japan & & & $-1.927^{* * *}$ & $-1.211^{* *}$ \\
& & & $(0.139)$ & $(0.471)$ \\
Unsolicited $\times$ Finance & & & $-2.810^{* * *}$ & $-1.465^{* * *}$ \\
& No & No & $(0.117)$ & $(0.484)$ \\
Other covariates & 163381 & No & Yes \\
Observations & Yes & Yes & Yes & Yes \\
Year FE & Yes & No & No & No \\
Region FE & Yes & Yes & Yes & Yes \\
Sector FE & No & Yes & Yes & Yes \\
Country FE & 0.32 & 0.41 & 0.42 & 0.28 \\
$R$-squared & 2155.25 & 646.72 & 645.02 & 77.83 \\
$F$-statistic & & & & \\
\hline
\end{tabular}

Notes: Rating level is the long-term foreign currency issuer ratings by S\&P between 1996 and 2016. Ratings have been transformed into a numerical scale from 0 (D/SD) to 21 (AAA). Unsolicited dummy is a dummy variable that takes the value of 1 if the rating is unsolicited and 0 if the rating is solicited. Unsolicited $\times$ Japan is the interaction between the Unsolicited dummy and a dummy that takes value the value of 1 for Japan and 0 otherwise. Unsolicited $\times$ Finance is the interaction between the Unsolicited dummy and a dummy that takes the value of 1 for the financial sector and 0 otherwise. Significance ${ }^{*} p<0.1,{ }^{* *} p<0.05$, $* * * p<0.01$.

where the subindex $i$ represents the individual (firm or institution), $k$ represents the sector, $r$ the region, and $t$ is the year. $\alpha$ is a constant, $X_{i, t}$ a vector of controls that may change at the individual level, at the time level or both, and Unsolicited ${ }_{i, t}$ is a dummy variable that takes the value of 1 if the rating is unsolicited and 0 if it is not. $\lambda_{k}, \tau_{t}, \rho_{r}$ and $\delta_{c}$ are sector, time, region and country fixed effects.

The coefficient of interest - $\beta$ - measures how much the rating level changes if a rating is defined as unsolicited. A positive number means that the grade is higher for unsolicited ratings than for solicited ratings with similar observable characteristics. Table 3 is the panel regression for all sectors. Overall, the effect of the solicitation status on the rating level is negative and significant. Hence, unsolicited ratings are generally lower. The coefficient $\beta$ in column (1) is almost the difference between the "+" and the "-" modifier, but is less than one notch difference. Column (2) adds country fixed effects and column (3) adds two interaction terms: the effect of having unsolicited ratings in Japan and in the financial sector. This is motivated by the suspicion that financial companies and Japanese companies may have faced particularly biased downward ratings. I confirm that the negative sign of $\beta$ is driven by these two groups and, once they are taken into account, the baseline for unsolicited ratings becomes positive. The last column presents the results of estimating Equation (3.1) on the subsample for which I have financial controls at the firm level. 
Controlling for individual fundamentals, as well as being a Japanese firm or being in the financial sector, the negative bias persists.

Running the regression separately for different sectors (financial, non-financial, and government) yields different results. Table 4 shows that the unsolicited status is associated with ratings up to 3 points lower in the financial sector and insignificant in the non-financial sector. In the government sector, on the contrary, unsolicited ratings are higher.

In Table 5, I further control for the financial characteristics of the borrower in a reduced subsample of firms (those belonging to the S\&P Global 1200 index, the Nikkei 225, and Datastream financial sector composite index). ${ }^{\mathrm{m}}$ As expected, I find that the coefficient $\beta$ is the largest and it is significantly negative for firms belonging to the financial sector - the subsector of banks and insurance companies - and, in this case, it is also negative for most of the non-financial sectors (industrials, materials, healthcare, technology, and consumer discretionary). For utilities, the effect is positive (2.19 points difference in favor of unsolicited ratings). In the government sector, we use only the subsample of sovereigns for which we have economic variables as controls. Sovereigns also show a positive and sizeable difference in average ratings in favor of the unsolicited group. This last piece of evidence is difficult to reconcile with theories of a downward bias in unsolicited ratings, and it is more natural to think that selection plays an important role in the differences across groups. ${ }^{\mathrm{n}}$

The results are consistent if I estimate instead an ordered probit that takes into account only the ordinal difference between rating grades. However, the coefficient of the ordered probit ${ }^{\circ}$ does not have a direct interpretation in terms of rating notches and rating modifiers; thus, I report the linear regression analysis instead.

Selection into the solicitation status has an effect on the equilibrium interest rate. Solicited and unsolicited bonds could have different yields, despite being of the same rating grade, and the theory predicts the direction in which they should go. In the equilibrium with positive selection, markets understand that a high unsolicited rating grade, which reveals a creditworthy type, is less risky than a high solicited grade (which can also be the riskier type). Accordingly, the interest rate they demand on unsolicited bonds should be lower. The opposite is true for the equilibrium with negative selection. In this case, we should expect a higher interest rate on unsolicited bonds with respect to solicited bonds with the same grade, because the expected probability of default (which is unbiased) differs across the two groups. Past empirical literature may have underestimated the importance of selection, assuming that once the rating level has been controlled for there should be no difference in market value or ex-post default probability if only selection was at work. As a result, they attributed any additional effect to a strategic component. In order to analyze the market valuation of the solicitation status and whether it changes sign

$\mathrm{m}$ The subsample is not random; it could be biased towards large quoted firms.

${ }^{n}$ Rating inflation is an explanation of why some ratings could be upward biased. However, since unsolicited ratings are not paid for, this group is the least likely to be subject to rating inflation.

${ }^{\circ}$ Results are available upon request. 


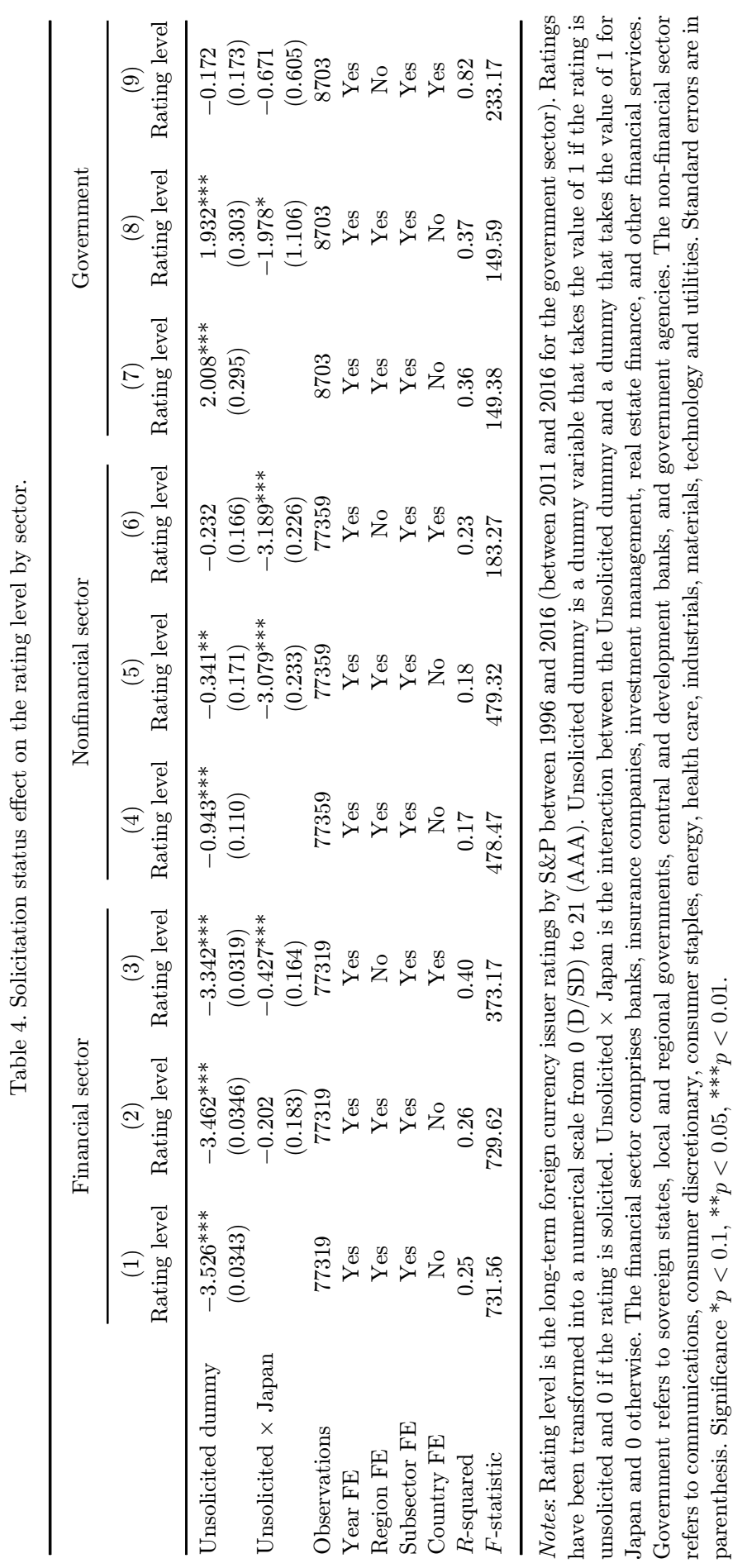




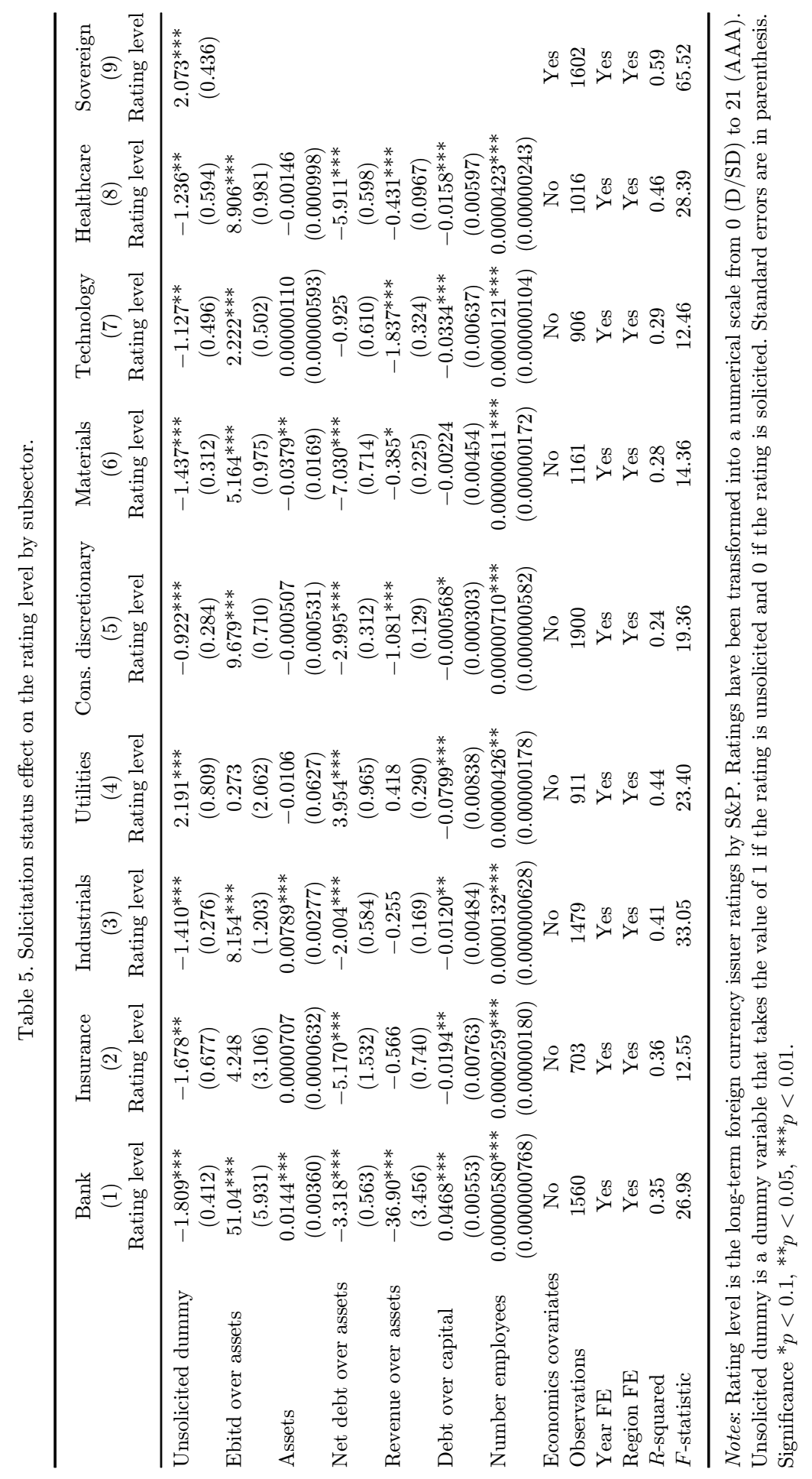


Table 6. Effect of the solicitation status on sovereign yields.

\begin{tabular}{|c|c|c|c|c|}
\hline & $\begin{array}{c}(1) \\
\text { Sovereign yield }\end{array}$ & $\begin{array}{c}(2) \\
\text { Sovereign yield }\end{array}$ & $\begin{array}{c}(3) \\
\text { Sovereign yield }\end{array}$ & $\begin{array}{l}(4) \\
\text { Sovereign yield }\end{array}$ \\
\hline Unsolicited dummy & $\begin{array}{c}-0.379 \\
(0.277)\end{array}$ & $\begin{array}{l}-1.171^{* * *} \\
(0.253)\end{array}$ & $\begin{array}{r}-0.431^{*} \\
(0.248)\end{array}$ & $\begin{array}{c}-1.138^{* * *} \\
(0.398)\end{array}$ \\
\hline Rating level & $\begin{array}{c}-0.577^{* * *} \\
(0.0443)\end{array}$ & & $\begin{array}{c}-0.289^{* * *} \\
(0.0483)\end{array}$ & $\begin{array}{c}-0.393^{* * *} \\
(0.0977)\end{array}$ \\
\hline Current account & & $\begin{array}{c}-0.0691^{* *} \\
(0.0345)\end{array}$ & $\begin{array}{c}-0.0111 \\
(0.0314)\end{array}$ & $\begin{array}{c}-0.178 * * * \\
(0.0388)\end{array}$ \\
\hline Gross debt & & $\begin{array}{c}0.00806 \\
(0.00506)\end{array}$ & $\begin{array}{c}-0.00272 \\
(0.00421)\end{array}$ & $\begin{array}{c}-0.0844^{* * *} \\
(0.0140)\end{array}$ \\
\hline Primary lending & & $\begin{array}{c}-0.0150 \\
(0.0495)\end{array}$ & $\begin{array}{c}-0.0890^{*} \\
(0.0458)\end{array}$ & $\begin{array}{c}-0.0813^{* *} \\
(0.0376)\end{array}$ \\
\hline Revenue & & $\begin{array}{c}-0.0545^{* * *} \\
(0.0110)\end{array}$ & $\begin{array}{c}-0.0129 \\
(0.0117)\end{array}$ & $\begin{array}{c}0.0673 \\
(0.0564)\end{array}$ \\
\hline GDP & & $\begin{array}{l}-0.602^{* * *} \\
(0.107)\end{array}$ & $\begin{array}{c}-0.381^{* * *} \\
(0.0971)\end{array}$ & $\begin{array}{l}1.425^{* * *} \\
(0.509)\end{array}$ \\
\hline Inflation & & $\begin{array}{l}0.164^{* * *} \\
(0.0591)\end{array}$ & $\begin{array}{c}0.121^{* *} \\
(0.0516)\end{array}$ & $\begin{array}{c}-0.0265 \\
(0.0173)\end{array}$ \\
\hline Population & & $\begin{array}{l}0.0251^{* * *} \\
(0.00532)\end{array}$ & $\begin{array}{l}0.0194^{* * *} \\
(0.00511)\end{array}$ & $\begin{array}{c}-0.272^{* * *} \\
(0.0700)\end{array}$ \\
\hline Unemployment rate & & $\begin{array}{l}0.204^{* * *} \\
(0.0371)\end{array}$ & $\begin{array}{l}0.132^{* * *} \\
(0.0341)\end{array}$ & $\begin{array}{l}0.373^{* * *} \\
(0.0632)\end{array}$ \\
\hline Country FE & No & No & No & Yes \\
\hline Observations & 348 & 308 & 308 & 308 \\
\hline$R$-squared & 0.52 & 0.58 & 0.65 & 0.87 \\
\hline$F$-statistic & 105.29 & 38.10 & 38.28 & 29.81 \\
\hline
\end{tabular}

Notes: Sovereign yield is the annual interest rate on government bonds. Ratings have been transformed into a numerical scale from 1 (C) to 21 (Aaa) for Moody's. Unsolicited dummy is a dummy variable that takes the value of 1 if the rating is unsolicited and 0 if the rating is solicited. Standard errors are in parenthesis. Significance ${ }^{*} p<0.1,{ }^{* *} p<0.05,{ }^{* * *} p<0.01$.

for different sectors as predicted by the theory, I run the following regression:

$$
\text { Stock price }_{i, t}=\delta \text { Unsolicited }_{i, t}+\lambda X_{i, t}+\tau_{t}+\rho_{r}+u_{i, t},
$$

where the subindex $i$ represents the individual (firm or institution), $r$ the region, and $t$ is the year. $X_{i, t}$ a vector of controls that may change at the individual level, at the time level or both and Unsolicited $_{i, t}$ is a dummy variable that takes the value of 1 if the rating is unsolicited and 0 if it is solicited. $\tau_{t}$, and $\rho_{r}$ are time and region fixed effects.

Table 6 presents the effect of the solicitation status by Moody's on sovereign yields. ${ }^{\mathrm{p}}$ The coefficient of the solicitation status is negative, indicating that the sovereign yields of a borrower with an unsolicited rating are lower than those of a borrower with a solicited rating for the same rating level. This means that borrowers receiving an unsolicited rating have to pay less for their debt, consistent with the

PFor this part of the analysis I have to look at Moody's ratings, instead of S\&P, due to availability of sovereign yields. 


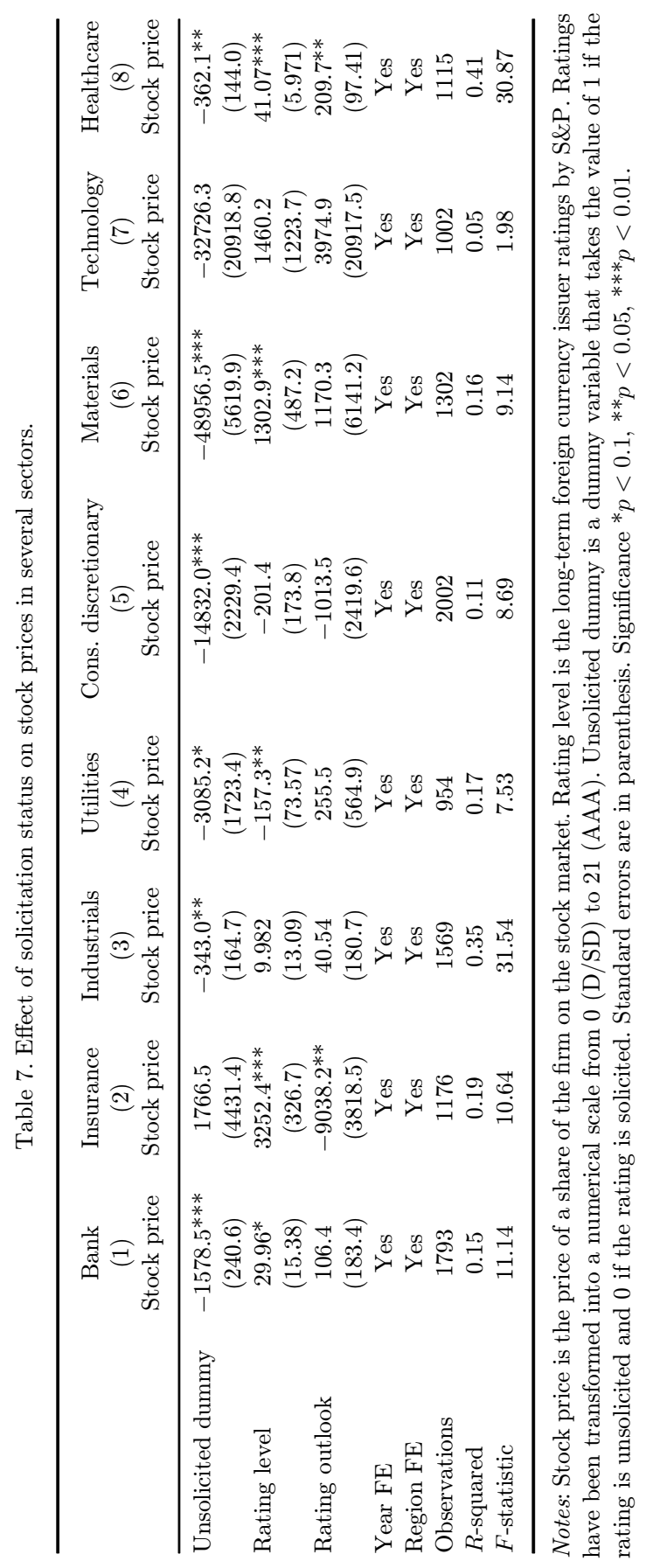




\section{A. Gibert}

market beliefs that they are more creditworthy because of positive selection in unsolicited ratings.

For the other sectors, the effect of solicitation status on stock price can be found in Table 7. An unsolicited rating is associated, when significant, to a lower valuation of the company in the stock market compared to the same solicited ratings in the same sector at the same time. If investors were concerned about firms being unduly punished with lower unsolicited ratings by strategic CRAs, this would presumably imply higher rather than lower stock prices for these firms. The selection hypothesis, on the contrary, works in the direction of the evidence reported here.

\section{Conclusion}

In this paper, I study the extent to which selection is one of the driving factors behind the differences in rating grades and other credit market outcomes between borrowers with solicited and unsolicited rating status. Some sectors are arguably more visible than others or induce the rating agencies to issue more unsolicited ratings. Firms in those sectors may react to the higher chance of receiving an unsolicited rating. In particular, less creditworthy borrowers are those whose incentives to avoid ratings are the highest. The fact that they will take steps in that direction modifies the quality of the pool of borrowers rated without solicitation. Using a panel of S\&P long-term issuer ratings, I find that in the government sector we see a positive selection of borrowers into unsolicited ratings.

Another prediction of the model is that selection has an effect on the equilibrium interest rate. In markets with negative selection, we should expect a lower price on unsolicited bonds with respect to solicited bonds with the same grade. The opposite is true for the markets with positive selection. I find confirmation of these predictions in the data.

There have been numerous attempts to regulate the issuance of unsolicited ratings on the part of the rating agencies. The results of this paper indicate that, without taking into account the whole portfolio of services that the agencies offer (including confidential ratings), the efforts to supervise the credit rating business may be incomplete.

\section{Acknowledgements}

I am grateful to Piero Gottardi, Arpad Abraham, Vito Polito, two anonymous referees and the participants at the DIW working group, the 48th Money, Macro and Finance Research Group Annual Conference, and the Economic Theory seminar at the University of Malaga for their helpful comments. The author acknowledges financial support from the Baffi Carefin Centre for applied research on international markets, banking, finance, and regulation. 


\section{References}

C. Bannier, P. Behr \& A. Guettler (2010). Rating opaque borrowers: Why are unsolicited ratings lower? Review of Finance 14, 263-294.

A. Bolger \& R. Wigglesworth (2014). Dash for trash lifts unrated debt sales, The Financial Times.

S. Byoun, Soku \& Shin, Yoon (2002). Unsolicited Credit Ratings: Theory and Empirical Analysis. SSRN Electronic Journal. 10.2139/ssrn.354125.

S. Byoun \& Y. S. Shin (2012). Information content of unsolicited credit ratings: Evidence from japanese firms. Asia-Pacific Journal of Financial Studies 41 (1), 59-86.

ESMA (2015). Competition and choice in the credit rating industry, European Securities and Markets Authority, 18 December 2015, <https://www.esma.europa.eu/sites/default/ files/library/2015-1879_esma_cra_market_share_calculation.pdf $>$.

P. Fulghieri, G. Strobl \& H. Xia (2014). The economics of solicited and unsolicited credit ratings, Review of Financial Studies 27 (2), 484-518.

Y. H. Gan (2004). Why do firms pay for bond ratings when they can get them for free?

H. Langohr \& P. Langohr (2008). The Rating Agencies and their Credit Ratings: What They are, How they Work and Why they are Relevant. England: John Wiley; NJ: Hoboken.

A. Lizzeri (1999). Information revelation and certification intermediaries, RAND Journal of Economics 30 (2), 214-231.

J. Mathis, J. McAndrews \& J. Rochet (2009). Rating the raters: Are reputation concerns powerful enough to discipline rating agencies? Journal of Monetary Economics 56 (5), 657-674.

W. Poon (2003). Are unsolicited credit ratings biased downward? Journal of Banking 83 Finance 27 (4), 593-614.

W. Poon \& M. Firth (2005). Are unsolicited credit ratings lower? international evidence from bank ratings, Journal of Business Finance E Accounting 32 (9-10), 1741-1771.

W. Poon, J. Lee \& B. Gup (2009). Do solicitations matter in bank credit ratings? results from a study of 72 countries, Journal of Money, Credit and Banking 41, 285-314.

W. P. Poon \& K. C. Chan (2010). Solicited and unsolicited credit ratings: A global perspective, ADBI Working Paper Series, Vol. 244, 2010.

Standard \& Poor's (2011a). Ratings On Seven European Sovereigns And The European Central Bank Converted To Unsolicited Ratings, S\&P Global Ratings' Credit Research, 17 February 2011. New York, NY: Alacra Store. Retrieved 27 December $2019<$ http:// www.alacrastore.com/s-and-p-credit-research/Ratings-On-Seven-European-Sovereigns-And-The-European-Central-Bank-Converted-To-Unsolicited-Ratings-849155>.

Standard \& Poor's (2011b). S\&P converts US ratings to "unsolicited", Thomson Reuters, 24 February 2011, <https://uk.reuters.com/article/usa-ratings-sandp/sp-converts-usratings-to-unsolicited-idUKWNA191720110224>.

Standard \& Poor's (2011c). Ratings On Six Asia-Pacific Sovereigns Converted To Unsolicited Ratings, S\&P Global Ratings' Credit Research, 28 February 2011. Thailand Press Release. Retrieved 27 December $2019<$ https://www.ryt9.com/es/prg/106005>.

Standard \& Poor's (2017). S\&P Global Ratings Definitions, S\&P Global Ratings' Credit Research, 26 June 2017. Retrieved 27 December $2019<$ https://www.standardandpoors.com/en'EU/delegate/getPDF?articleId=2017758\&type=COMMENTS\& subType $=$ REGULATORY $>$.

The Economist (2001). Credit-rating agencies: New interests, new conflicts', The Economist, 12 April 2001, print edition. Accessed 27 December $2019<$ https://www.economist. com/finance-and-economics/2001/04/12/new-interests-new-conflicts $>.2001 / 04 / 12$ / new-interests-new-conflicts $>$.

P. Van Roy (2013). Is there a difference between solicited and unsolicited bank ratings and, if so, why? Journal of Financial Services Research 44 (1), 53-86.

L. J. White, The credit rating agencies, Journal of Economic Perspectives 24 (2), 211-226. 